\title{
SEOR recommendations on the use of protons
}

\author{
M. Lloret-Saez-Bravo ${ }^{1} \cdot$ J. Giralt-L de Sagredo ${ }^{2} \cdot$ J. Contreras-Martinez ${ }^{3} \cdot$ C. Ferrer-Albiach ${ }^{4} \oplus$
}

Received: 17 July 2019 / Accepted: 25 July 2019 / Published online: 12 August 2019

(c) Federación de Sociedades Españolas de Oncología (FESEO) 2019

\section{Introduction}

Radiotherapy is one of the fundamental strategies in the treatment of cancer that is used in more than $60 \%$ of patients with this disease. It can be used with curative intention or to alleviate symptoms, always trying to minimize toxicity in healthy tissues.

In "classical" radiotherapy, essentially photons are used. Proton therapy (PTR) is a special modality of radiotherapy that uses heavy particles (protons) instead of X-rays. These particles stand out above all due to their characteristic dose distribution in the tissues they pass through, with the maximum dose being deposited before their arrest, what is called Bragg's Peak [1].

The first proton treatments began in 1954 at the Lawrence Berkeley Laboratory (California). In the following years, different publications show that proton beam therapy can reach cure rates higher than traditional therapy in tumors located in areas inaccessible to surgery and surrounded by vital tissues [2].

However, the use of protons in clinical practice has been very restricted, among other reasons, because it is a treatment that is difficult for patients to access because it is available in a limited number of centers.

$\triangle$ C. Ferrer-Albiach

ferreralbiach@gmail.com

1 Department of Radiation Oncology, Hospital Universitario de Gran Canaria Dr Negrín, Las Palmas de Gran Canaria, Spain

2 Radiation Oncology Department, Vall d'Hebron University Hospital, Vall d'Hebron Institute of Oncology, Barcelona, Spain

3 Radiation Oncology Department, Hospital Regional Málaga, Head GenesisCare Málaga, Málaga, Spain

4 Radiation Oncology Department, Consorcio Hospitalario Provincial de Castellón, Avda. Dr Clara 19, 12002 Castellón, Spain
In Europe, this treatment is available in many countries, being the most traditional France, Germany and Italy (Table 1).

The implementation in the near future in Spain of proton therapy units has led to the preparation of a document by the Spanish Society of Radiation Oncology on "Recommendations on the use of protons", with the dual purpose of reporting this treatment to professionals related to oncology and that serve as a reference to support the use of it. This document comes to fill an orphan space in our environment, despite the fact that in Spain a good number of patients for PTR are referred to centers outside our borders every year.

\section{What are its benefits?}

The proton therapy represents a potential clinical improvement of the radiotherapy treatment, since its physical and radiobiological properties have dosimetric advantages in comparison with the irradiation with photons or electrons of the conventional linear accelerators.

PTR allows a more precise and localized release of radiation, with a better potential distribution of the radiation dose in the tumor tissue and a greater preservation of the surrounding healthy tissue than conventional radiotherapy with photons or electrons. This characteristic would allow, in theory, the application of the same therapeutic dose with less toxicity or adverse effects and/or apply a greater dose of radiation without increasing the toxicity in the surrounding healthy tissues.

According to the above, the advantages of proton treatment would be the reduction of late adverse effects and the reduction of the risk of developing second tumors, due to a decrease in the dose to normal tissue. This becomes relevant in long surviving patients, especially in the pediatric population [3-5]. In addition, because of the dose limited to healthy tissues, an escalation of doses can be performed, making it possible to improve the control of tumors with histologies resistant to radiation, such as chordomas or chondrosarcomas of the base of the skull [6]. 
Table 1 Proton therapy centers in Europe by country and start-up year

\begin{tabular}{lll}
\hline Country & $\begin{array}{l}\text { Number of } \\
\text { facilities }\end{array}$ & Start-up year \\
\hline Switzerland & 1 & 1984 \\
France & 3 & 1991,2017 \\
Germany & 7 & $1998,2009,2013,2014$ \\
Italy & 2 & 2009,2012 \\
Czech Republic & 1 & 2012 \\
Poland & 1 & 2013 \\
Sweden & 1 & 2013 \\
Netherlands & 4 & $2015,2017,2019$ \\
United Kingdom & 2 & 2017,2018 \\
Belgium & 1 & 2018 \\
\hline
\end{tabular}

\section{Indications}

Despite all the advantages discussed above, the emergence of proton therapy represents a recurrent problem in Radiation Oncology, since technological evolution is faster than the performance of clinical studies with the highest level of evidence demonstrating its clinical benefit. There are currently a limited number of studies comparing proton treatment with photon therapy. However, the dosimetric advantages objectified in practically all the possible tumor locations, advocates prioritizing the use of PTR for patients with high survival rates and/or young patients.

We must highlight two fundamental aspects to be evaluated in the indication of proton treatment: the prevention/reduction of side effects (late toxicity and/or second tumors) and the improvement of local control by escalation of doses in radioresistant tumors.

According to the American Society of Radiation Oncology (ASTRO, 2012), the use of protons is justified in those situations in which an advantage is observed and which are included in the so-called Group 1 of the recommendations. From SEOR, an adaptation is made based on four principles: tumors close to critical structures, need to irradiate the volume in a homogeneous way, reduction of the integral dose or in the case of re-irradiation. In this way, the use of protons in the following clinical situations is recommended:

1. Ocular tumors, including ocular melanomas.

2. Tumors near or at the base of the skull, including chordoma and chondrosarcoma.

3. Primary or metastatic tumors in the spinal cord, where the tolerance of the cord can be overcome with conventional treatment or in cases in which the medullary cord has already been irradiated.
4. Primary or benign solid tumors in the pediatric population, subsidiary of treatment with curative intent, mainly those located in the CNS and/or near risk organs (marrow, heart, lungs).

5. Patients with genetic syndromes with high risk of toxicity.

6. Patients who must receive re-irradiation, in which the dose that the critical structures will receive exceeds the tolerance dose.

In these, recommendations should be considered as a limitation, the fact of having to move the patient away from their family environment and care to receive treatment. In addition, in those care settings with scarce resources in PTR, a patient selection methodology should perhaps be established [7].

\section{Needs in Spain}

After reviewing the literature from different scientific societies [8-12], it is estimated that the percentage of treatments with protons in Spain is located in the short term in $2 \%$ of cancer patients who are going to receive radiotherapy and in the medium term in the $11 \%$ of patients, from a clinical prescription point of view. This would range from the most restrictive situation only with the standard indications, 725 patients, to include all possible indications with a total of 17,671 patients.

The number of patients treated per year per treatment room varies between 200 and 280 depending on the experience of the center. This would imply the need in Spain for a minimum of three treatment rooms, taking into account the more restrictive situation of the indications mentioned above.

This estimate is very conservative, since the commonly accepted indications for proton therapy have increased significantly since 2009 (date of the report of the Ministry of Health of the Netherlands, one of the most exhaustive) as demonstrated by the subsequent bibliography. Future revisions of this document will give way to new indications.

\section{Compliance with ethical standards}

Conflict of interest There is no conflict of interest of the authors.

Ethical approval All procedures performed in studies involving human participants were in accordance with the ethical standards of the institutional and/or national research committee and with the1964 Helsinki Declaration and its later amendments or comparable ethical standards.

Informed consent No informed consent is necessary as it is an opinion letter (editorial). 


\section{References}

1. Herranz E. I Encuentro complutense para la divulgación en Física Nuclear y de partículas. 2008.

2. Doyen J, Tuan Falk A, Floquet V, Hérault J, Hannoun-Lévi $\mathrm{J}-\mathrm{M}$. Proton beams in cancer treatments: clinical outcomes and dosimetric comparisons with photon therapy. Cancer Treat Rev. 2016;43:104-12.

3. Armstrong GT, Liu Q, Yasui Y, et al. Late mortality among 5-year survivors of childhood cancer: a summary from the Childhood Cancer Survivor Study. J Clin Oncol. 2009;27:2328-38.

4. Turcotte LM, Whitton JA, Friedman DL, et al. Risk of subsequent neoplasms during the fifth and sixth decades of life in the childhood cancer survivor study cohort. J Clin Oncol. 2015;33:3568-78.

5. Yock TI, Yeap BY, Ebb DH, et al. Long-term toxic effects of proton radiotherapy for paediatric medulloblastoma: a phase 2 single-arm study. Lancet Oncol. 2016;17(3):287-98.

6. Feuvret L, Bracci S, Calugaru V, Bolle S, Mammar H, De Marzi L, et al. Efficacy and safety of adjuvant proton therapy combined with surgery for chondrosarcoma of the skull base: a retrospective, population-based study. Int J Radiat Oncol Biol Phys. 2016;95(1):312-21. https://doi.org/10.1016/j.ijrobp.2015.12.016 (Epub 2015 Dec 17 PubMed PMID: 26883563).

7. Langendijk JA, et al. Selection of patients for radiotherapy with protons aiming at reduction of side effects: The model-based approach. Department of Radiation Oncology, University Medical Center Groningen, University of Groningen, The Netherlands. Radiother Oncol. 2013;107:267-73.

8. National PBS Developmment programme-Strategic Outline Case. https://www.gov.uk/government/publications/national-proto n-beam-therapy-service-development-programme.

9. Proton Radiotherapy. Horizon scanning report. The Hague: Health Council of the Netherlands, 2009; publication no. 2009/17E. ISBN: 978-90-5549-786-7

10. Patel S, Kostaras X, Parliament M, Olivotto IA, Nordal R, Aronyk K, Hagen N. Recommendations for the re-ferral of patients for proton-beam therapy, an Alberta Health Services report: a model for Canada? Curr Oncol. 2014;21(5):251-62. https://doi. org/10.3747/co.21.2207.

11. Grau M. La protonterapia en el tratamiento del cáncer. Actualización. Barcelona: Ministerio de Sanidad, Servicios Sociales e Igualdad. Agència de Qualitat i Avaluació Sanitàries de Catalunya. Departament de Salut. Generalitat de Catalunya; 2018 (Informes de Evaluación de Tecnologías Sanitarias). (C) 2018 Ministerio de Sanidad, Servicios Sociales e Igualdad.

12. ASTRO PBT model policies. https://www.astro.org/protonmp.

Publisher's Note Springer Nature remains neutral with regard to jurisdictional claims in published maps and institutional affiliations. 